\title{
Standard perioperative management in gastrointestinal surgery
}

\author{
Marian Grade • Michael Quintel • B. Michael Ghadimi
}

Received: 20 January 2011 / Accepted: 8 March 2011 /Published online: 30 March 2011

(C) The Author(s) 2011. This article is published with open access at Springerlink.com

\begin{abstract}
Introduction The outcome of patients who are scheduled for gastrointestinal surgery is influenced by various factors, the most important being the age and comorbidities of the patient, the complexity of the surgical procedure and the management of postoperative recovery. To improve patient outcome, close cooperation between surgeons and anaesthesiologists (joint risk assessment) is critical. This cooperation has become increasingly important because more and more patients are being referred to surgery at an advanced age and with multiple comorbidities and because surgical procedures and multimodal treatment modalities are becoming more and more complex.

Objective The aim of this review is to provide clinicians with practical recommendations for day-to-day decisionmaking from a joint surgical and anaesthesiological point of view. The discussion centres on gastrointestinal surgery specifically.
\end{abstract}

Keywords Perioperative management $\cdot$ Risk assessment . Gastrointestinal surgery. Practical recommendations

M. Grade $\cdot$ B. M. Ghadimi $(\bowtie)$

Department of General and Visceral Surgery, University Medical

Center Göttingen,

Robert-Koch Str. 40,

37075 Göttingen, Germany

e-mail: mghadim@uni-goettingen.de

M. Quintel

Department of Anaesthesiology, Emergency and Intensive Care

Medicine, University Medical Center Göttingen,

Robert-Koch Str. 40,

37075 Göttingen, Germany

\section{Introduction}

The outcome of patients who undergo gastrointestinal surgery varies greatly. Factors such as the patient's age and comorbidities, the complexity of the surgical procedure and the management of postoperative recovery influence the outcome $[1,2]$. Modern perioperative management has been improved in numerous ways over the last decade and nowadays is regarded as a highly multidisciplinary task (Fig. 1). Because an ageing population is leading to more and more patients with multiple comorbidities being referred to surgery and because surgical procedures and multimodal treatment modalities are becoming increasingly complex, close cooperation between surgeons and anaesthesiologists (i.e. joint risk assessment) is critical for improving outcome after major gastrointestinal surgery. Internists are also frequently involved to optimise the patient's physical condition or medication.

It is beyond the scope of this review to comprehensively summarise the body of literature on perioperative management. Rather, we aim to provide clinicians with practical recommendations from a joint surgical and anaesthesiological point of view, with a specific emphasis on nonemergency gastrointestinal surgery. Because adequately powered randomised clinical trials are often lacking, some of these recommendations and suggestions are more empirical than evidence based. In addition, these recommendations partially represent the dayto-day practice at our University Medical Center.

\section{Preoperative management}

Medical history and clinical assessment

A detailed medical history and a thorough clinical assessment of the patient's physical and psychological 
Fig. 1 Basic principles of modern perioperative management to improve patient outcome after major gastrointestinal surgery

\section{Preoperative}

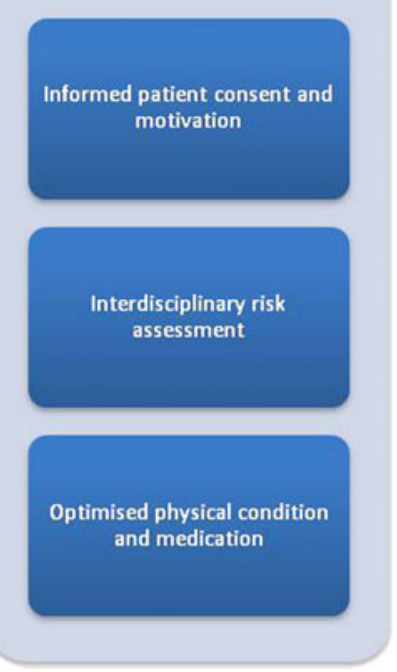

Intraoperative

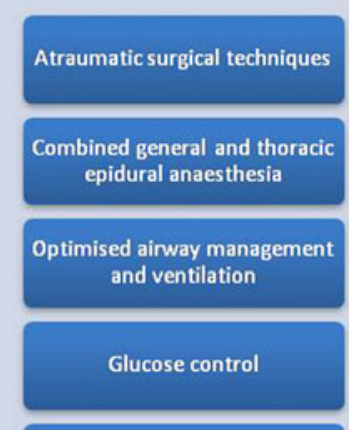

Optimised fluid management

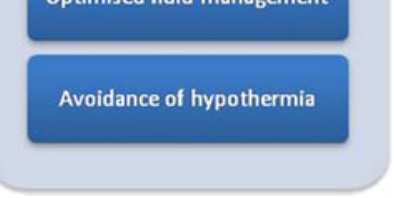

Postoperative

Modern opioid-sparing analgesia

Early mobilisation, prevention of venous thromboembolism

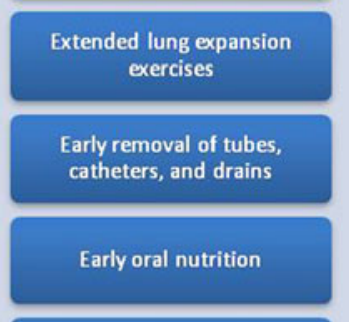

Early detection of complications condition are of utmost importance, as it may help to identify patient risk factors for imminent morbidity or mortality (e.g. an unappreciated reduction of physical fitness, specific medications or newly developed medical illness). Ideally, the medical history is taken, and the assessment performed before the patient's admission to the hospital so that certain medical conditions can be optimised (e.g. stabilisation of chronic heart failure, poorly controlled diabetes mellitus or arterial hypertension). However, when surgery is required for a gastrointestinal malignancy, a thorough pre-admission assessment may not be wise because it could substantially delay surgery.

\section{Routine diagnostic tests}

Close interaction between surgeons and anaesthesiologists is critical for improving patient outcome after major gastrointestinal surgery, and risk assessment should always be joint. There are routine test results that should be available before the patient is referred to anaesthesiology consultation (modified from [3]).

\section{Laboratory tests}

Preoperative laboratory testing should be performed for all patients prior to gastrointestinal surgery. At minimum, the testing should consist of:

- Standard blood count

- International normalised ratio

- Activated partial thromboplastin time (aPTT)

- Concentrations of sodium, potassium, creatinine and glucose
Certain procedures or clinical conditions may require additional assessments. Occasionally, a laboratory test may be required on the day of surgery (e.g. serum potassium levels after extensive mechanical bowel preparation (MBP) or glucose levels for patients with severe diabetes mellitus). Recent data have indicated that an elevated preoperative level of brain natriuretic peptide is associated with increased cardiac morbidity after major surgery, but it remains to be seen whether this level will be routinely determined for patients with cardiac risk factors [4-6].

\section{Electrocardiography}

Preoperative 12-channel electrocardiography (ECG) allows for screening of as-yet undetected cardiac disorders. It also serves as a control should perioperative cardiac complications occur. ECG should be performed for patients who:

- Are $>40$ years old

- Have relevant cardiac disorders (e.g. coronary artery disease, heart insufficiency, heart rhythm disturbances or valve disorders)

- Have a pacemaker (PM) or implanted cardioverter/ defibrillator (ICD)

- Have newly developed pulmonary or cardiac symptoms

- Are receiving preoperative chemotherapy or chemoradiotherapy

Although it is not routine practice, many clinicians recommend that for patients with coronary artery disease who underwent high-risk surgery, an additional ECG should be obtained immediately after surgery as well as on days 1 and 2 postoperatively. 


\section{Chest radiography}

The sensitivity of conventional chest radiography to detect pathophysiologic conditions in asymptomatic patients is relatively low. However, X-ray images may always serve as a basis for comparison should perioperative complications occur. While there is currently no recommendation for preoperative chest radiography for patients with an American Society of Anesthesiologists score 1-2, regardless of the patient's age, it is indicated for patients who:

- Suffer from severe chronic obstructive pulmonary disease

- Developed yet unknown pulmonary or cardiac symptoms

- Have gastrointestinal malignancies (screening for pulmonary metastases)

Advanced diagnostic tests

After reviewing the results of routine diagnostic tests, the anaesthesiologist will likely request additional tests for certain patients or certain medical conditions (modified from [3]). Although not indicated for standard gastrointestinal surgery, these additional tests can help in the assessment of the potential risk for perioperative problems and complications.

\section{Echocardiography}

Preoperative echocardiography should be performed on patients who:

- Have newly occurring dyspnoea of unknown origin

- Have known heart insufficiency with symptoms of deterioration

- Have cardiomyopathy and have undergone preoperative chemotherapy with epirubicin (see "Chemotherapy and chemoradiotherapy" below)

\section{Carotid Doppler ultrasonography}

Preoperative carotid Doppler ultrasonography should be performed on patients who:

- Had experienced transient ischemic attack (TIA) or stroke within the preceding 3 months if the episode had occurred without proper follow-up medical assessment or diagnosis

- Had experienced TIA or stroke within the preceding 3 months if symptoms of deterioration have appeared
Preoperative risk assessment

Definition of "high risk"

The definition of being "high risk" for poor outcome after surgery is nebulous, as it is influenced by many variables that vary from patient to patient and from one surgical procedure to another [7]. The surgeon and anaesthesiologist need to jointly evaluate the potential perioperative risk for each patient and the intended procedure. Relevant clinical conditions that characterise high-risk surgical patients are listed in Table 1, and the top 10 clinical variables that influence 30-day and long-term mortality are highlighted in Table 2 (modified from Ackland and Edwards [7] and Khuri et al. [8]).

\section{Risk scores}

In an attempt to facilitate perioperative risk assessment, a variety of scoring systems have been developed that incorporate the patient's age and comorbidities and the complexity of the surgical procedure. Well-known systems include the Physiological and Operative Severity Score for the Enumeration of Mortality and Morbidity [9] and the Estimation of Physiologic Ability and Surgical Stress score [10]. However, both systems indicate a general risk for complications and do not specify or pinpoint any specific complication. Accordingly, their implementation into routine clinical practice has proven to be difficult. Data from our University Medical Center suggest that the subjective opinion ("gut feeling") of the surgeon is a good predictor of postoperative outcome, especially in nonemergency surgery [11].

More recently, a risk calculator for colorectal surgery has been developed by the National Surgical Quality Improvement Program registry of the American College of Surgeons. After a patient's variables are entered, the risk probabilities for adverse outcome are calculated [12]. However, only registry members can access the calculator, and it is not clear whether this US hospital-based tool is applicable to European institutions.

\section{Cardiac risk evaluation}

Overall, gastrointestinal surgery is associated with a medium cardiac risk [13-16]. However, due to an ageing

Table 1 Clinical conditions that characterise high-risk surgical patients undergoing major gastrointestinal surgery

Coronary artery disease

Heart insufficiency

Renal failure

Poorly controlled diabetes mellitus

Older age 
Table 2 Top 10 clinical conditions that influence 30-day mortality and long-term mortality after major gastrointestinal surgery

\begin{tabular}{ll}
\hline 30-Day mortality & Long-term survival \\
\hline Any complication & Older age \\
ASA class & Albumin concn $(\mathrm{g} / \mathrm{dl})$ \\
Emergency surgery & Any complication \\
Albumin concn $(\mathrm{g} / \mathrm{dl})$ & ASA class \\
RBC units transfused & Blood urea nitrogen \\
intraoperatively & concn $>40 \mathrm{mg} / \mathrm{dl}$ \\
Older age & COPD \\
Sodium concn $<135 \mathrm{nmol} / 1$ & Smoking \\
Disseminated cancer & Diabetes \\
Blood urea nitrogen concn & Functional status \\
$>40 \mathrm{mg} / \mathrm{dl}$ & \\
SGOT $>40 \mathrm{IU} / \mathrm{ml}$ & Disseminated cancer \\
\hline
\end{tabular}

ASA American Society of Anaesthesiologists; conch concentration; $C O P D$ chronic obstructive pulmonary disease; $R B C$ red blood cells; $S G O T$ serum glutamic oxaloacetic transaminase

population, an increasing incidence of coronary artery disease and the increasing complexity of surgical procedures, postsurgical cardiac complications are now a leading cause of morbidity and mortality. Particularly cardiac insufficiency is emerging more and more as a risk factor for perioperative adverse outcome, even compared with cardiac ischemia [17]. Comorbidities that increase the cardiac risk for patients undergoing gastrointestinal surgery include:

- Coronary artery disease

- Heart insufficiency

- Severe aortic stenosis

- Peripheral artery disease

- Cerebrovascular insufficiency

- Renal failure

- Diabetes mellitus

Because both the assessment of these cardiac risk factors and their clinical interpretation are complicated, patients with diverse cardiac risk factors, acute symptoms of a cardiac disease or reduced physical fitness should be referred for consultation with an experienced cardiologist [13-16].

\section{Pulmonary risk evaluation}

Late postoperative pulmonary complications are the second-leading cause of morbidity and mortality after major surgery. For this reason, preoperative optimisation of the patient's physical condition and medication is important. Clinical parameters that represent risk factors for pulmonary complications after gastrointestinal surgery are listed in Table 3 (modified from [18, 19]). Although most of these risk factors cannot be circumvented, they must be kept under consideration [20].

\section{Medication}

Because the abrupt discontinuance of certain drugs may cause severe problems, a detailed medical history of the patient's medication is very important. In general, cardiovascular medication should be continued. Clear liquid intake (e.g. water or tea but not milk) is allowed until $2 \mathrm{~h}$ before anaesthesia, and solid food intake is recommended for up to $6 \mathrm{~h}$ prior to anaesthesia, so continuing medication usually does not create problems.

\section{Beta-adrenergic blockers}

Beta-adrenergic blockers are frequently used in the perioperative management of patients with cardiac disease due to their favourable effect on the supply and demand ratio of myocardial oxygen. Although still under debate, it is currently recommended that all patients who are already receiving beta-adrenergic blockers continue them perioperatively [14, 21]. Abrupt discontinuation can cause unstable angina, tachyarrhythmia, myocardial infarction and sudden death. If a patient who is scheduled for elective gastrointestinal surgery requires a new prescription, it should be started at least 1 month before the procedure to allow for dose adjustment $[14,21]$.

\section{Diuretics}

Diuretics should not be used on the day of surgery because this may increase the risk of intraoperative hypovolaemia.

Table 3 Clinical parameters that represent risk factors for pulmonary complications after gastrointestinal surgery

Patient-related factors

Congestive heart failure

ASA score $\geq 2$

Age $>60$ years

COPD

Functional dependence

Procedure-related factors

Abdominal surgery

Thoracic surgery

Surgery lasting $>3 \mathrm{~h}$

Emergency surgery

General anaesthesia

Laboratory-test-related factors

Serum albumin concn $<3.0 \mathrm{~g} / \mathrm{dl}$

ASA American Society of Anaesthesiologists; concn concentration; $C O P D$ chronic obstructive pulmonary disease 
However, it is strongly recommended that their intake be continued postoperatively, especially for patients who have heart failure.

\section{Metformin}

The relevance of the oral anti-diabetic drug metformin for inducing lactic acidosis has been controversially discussed in the literature [22]. Regardless, it is recommended that its intake be stopped $48 \mathrm{~h}$ prior to the surgery.

\section{Acetylsalicylic acid and thienopyridine derivatives}

Anti-platelet therapy (usually $100 \mathrm{mg}$ of acetylsalicylic acid daily) is standard for most patients with coronary artery disease. The 2009 European Society of Cardiology guidelines suggest that to reduce the risk of stent thrombosis and myocardial infarction, patients with a coronary bare metal stent (BMS) or a drug-eluting stent (DES) should receive anti-platelet therapy with both acetylsalicylic acid and a thienopyridine derivative (i.e., clopidogrel or ticlopidine) for 1 month (BMS) or 12 months (DES) after stent placement [14].

For patients who currently receive anti-platelet therapy and are scheduled for gastrointestinal surgery, the following wait times until surgery are recommended:

- After percutaneous transluminal coronary angioplasty without stent implantation: 2 weeks

- After BMS implantation: 6 weeks, but 3 months preferred

- After DES implantation: 1 year

For high-risk cardiac patients (i.e. patients with recent acute coronary syndrome, recurrent angina pectoris or recent surgical and conservative coronary intervention) who require major surgery that cannot be postponed, thienopyridine derivatives should be stopped 7-10 days before the surgery, whereas acetylsalicylic acid should be continued during the entire perioperative period [14, 2325]. This recommendation also applies to patients who require an epidural catheter.

\section{L-Dihydroxyphenylalanine}

L-Dihydroxyphenylalanine is the most frequently prescribed drug for Parkinson's disease. Because of its relatively short half-life, it should be continued during the entire perioperative period, as interrupting the medication can result in a life-threatening complication known as neuroleptic malignant-like syndrome, which is associated with fever, confusion and elevated concentrations of muscle enzymes [26].
Pacemaker or implantable cardioverter/defibrillator

An increasing number of patients who are referred to surgery have a PM or ICD. For these patients, the respective $\mathrm{PM} / \mathrm{ICD}$ pass must be available to health care providers at any time during the patient's hospital stay. Potential electromagnetic interferences during surgery require certain safety arrangements for the patient (Table 4). Unfortunately, evidence-based and uniformly accepted guidelines are lacking, and the large number of manufacturers and systems makes general safety recommendations extremely difficult [13, 27-29].

Mechanical bowel preparation

More than 10 years ago, Kehlet et al. first described a multimodal programme of enhanced postoperative recovery for elective surgery [30]. The basis of this fast-track methodology is the stepwise combination of singlemodality, evidence-based interventions [30-32] (for a more comprehensive review, please read the accompanying article "fast track perioperative management: physiologic principles"). A major intervention principle of this approach is the avoidance of MBP, particularly for patients undergoing elective colon surgery [33].

The mechanistic rationale for MBP prior to gastrointestinal surgery is to clean the large bowel of faeces, thereby

Table 4 Safety recommendations for patients with a PM or ICD who are undergoing gastrointestinal surgery

Recommendations for patients with a PM

Bipolar diathermy should always be the method of choice, as monopolar electrodes frequently induce interference. An ultrasonic scalpel is an alternative.

If monopolar diathermy is necessary, the neutral electrode should be placed as far away from the ICD system as possible, and the use of diathermy within a $15-\mathrm{cm}$ diameter of the system should be avoided. Short bursts of low energy with intermitting short breaks should be used.

A preoperative system check is recommended if the last one had occurred $>1$ year previously.

For patients who are PM dependent (permanent PM stimulation), an alternative external stimulation must be available.

A magnet should be available in case of PM malfunction.

Postoperative PM control is recommended if diathermy was used too close to the PM system. It is necessary if the system was reprogrammed preoperatively or if perioperative defibrillation occurred. The control should be performed in the anaesthetic recovery room or at the intensive care unit.

Additional recommendations for patients with an ICD

Preoperatively, the antitachycardia function of the ICD should be switched off and the availability of an external defibrillator ensured. A magnet should be available to disable the antitachycardia function of the ICD. 
reducing the probability of infection after colorectal resection and protecting a colorectal anastomosis. However, several prospective randomised trials have demonstrated that the outcome of patients who are scheduled for colorectal surgery is not significantly different for those who undergo MBP and those who do not [34-38]. In addition, extensive MBP may induce abdominal discomfort, nausea and pain; it may impair postoperative oral nutrition, and it may result in electrolyte imbalance and dehydration [39]. For these reasons, extensive MBP is not recommended any more.

The fast-track approach, however, is based primarily on open colorectal surgery, and it remains to be demonstrated whether avoidance of MBP can be directly translated into the laparoscopic setting, which is becoming more common for elective colorectal surgery. In addition, recent data from the French Research Group of Rectal Cancer Surgery III trial have indicated a higher risk of overall and infectious morbidity for patients who undergo rectal cancer surgery without MBP than with MBP, suggesting that this procedure be performed before elective rectal cancer surgery [40].

Our University Medical Center's approach to MBP is to perform preoperative enema on every patient scheduled for major gastrointestinal surgery. Moderate MBP (1 to 21 of polyethylene glycol) is recommended for certain surgical procedures, particularly rectal surgery.

Other preoperative considerations

\section{Smoking}

Because it creates cardiac stress, smoking increases the risk for perioperative complications, particularly for elderly patients with impaired cardiac function [41]. For this reason, systematic smoking intervention is highly recommended. To be of benefit, however, smoking cessation needs to occur several weeks prior to the surgery $[42,43]$.

\section{Nutritional support}

Although the exact clinical definition of malnutrition has not been established, it is well documented that poorly nourished patients are more likely to develop postoperative complications than well-nourished patients [44-46]. Accordingly, preoperative enteral and parenteral nutritional support has been recommended for malnourished patients $[47,48]$. For the general patient population, there is no evidence for preventive nutritional support.

\section{Obesity}

Obesity increases the rate of perioperative complications, increases morbidity and mortality after colectomy [49] and is a risk factor for postoperative intra-abdominal infection after gastrectomy [50]. In a recent study of obese patients who underwent Roux-en-Y bypass or laparoscopic adjustable gastric banding, 4.3\% developed a major adverse outcome within 30 days [51]. For those patients, a history of deep-vein thrombosis or pulmonary embolus, a diagnosis of obstructive sleep apnoea and impaired functional status represented independent risk factors for perioperative complications.

\section{Chemotherapy and chemoradiotherapy}

Due to the increasing complexity of modern concepts on cancer treatment, an increasing number of patients are receiving preoperative chemotherapy, either alone or with irradiation. Clinicians should be aware of four common side effects of frequently used chemotherapeutic agents and of radiotherapy. First, the anthracycline epirubicin, which is used to treat locally advanced gastric cancer, increases the risk for cardiomyopathy and heart failure, particularly among elderly patients with pre-existing cardiac disease [52]. Consequently, cancer patients with cardiomyopathy who received preoperative chemotherapy with epirubicin should be considered for a routine echocardiography, in addition to conventional electrocardiography, prior to any surgical procedure [53]. Second, the pyrimidine analogue 5fluorouracil, the most frequently used chemotherapeutic agent for gastrointestinal cancer, can induce coronary vasospams, myocardial ischemia and subsequent infarction [52]. Third, patients with gastrointestinal malignancy who receive the topoisomerase I inhibitor irinotecan are at risk for diarrhoea-induced malnutrition [52]. Fourth, radiotherapy is a cardiac risk factor for patients with cancer of the lower oesophagus or the gastroesophageal junction, and irradiation of rectal cancer can cause severe enteritis, malabsorption and diarrhoea $[54,55]$.

\section{Intraoperative management}

Prophylactic antibiotics

\section{Preoperative prophylaxis}

The goal of preoperative antimicrobial prophylaxis is to reduce the intraoperative bacterial load to a degree that can be controlled by the patient's innate immune system. The importance of adequate antimicrobial prophylaxis in preventing surgical site infection (SSI) is illustrated by its inclusion in World Health Organisation's surgical safety checklist and by the results of two trials of the use of such a list $[56,57]$. Even so, there are many questions to be answered and improvements to be realised before the optimal effect of this intervention can be achieved. 
For example, although the time to reach the plasma peak concentration is known for most antibiotic agents, very little is known about the time to achieve an adequate concentration on the skin or in other organs. In addition, the changes in haemodynamics caused by induction of anaesthesia and by the effects of any underlying disease might influence this timing. Intravenously applied beta-lactam antibiotics, which are commonly used as SSI prophylaxis, normally reach peak plasma concentration soon after their application, but their distribution to tissues depends on organ perfusion, plasma binding rate, molecular size and other factors. Studies by Stone and Classen have suggested that application should occur between 2 and $1 \mathrm{~h}$ before the skin incision [58, 59], and the World Health Organisation checklist advocates a 1-h interval (the commonly used 30min interval has never been rigorously investigated). Other studies have demonstrated that extension beyond $24 \mathrm{~h}$ actually leads to the emergence of resistant bacteria and higher rates of SSI [60].

Other issues in optimising the use of preoperative prophylactic antibiotics include the choice of drug in relation to the site and type of surgery, adequate dosing, early identification of potential additional patient risk factors and local characteristics of bacterial resistance. The surgical site will determine whether both Gram-negative and Gram-positive bacteria should be covered. The frequently used cephalosporins, for example, lose their Grampositive potency from generation to generation, whereas their Gram-negative potency increases (although this is not true for fifth-generation cephalosporins such as ceftobiprole, which recover their effectiveness against Grampositive germs). Cefazolin is suitable if preventing infection of the skin and deeper soft tissue (i.e. fascial and muscular layers) is the main goal. Third-generation cephalosporins are appropriate for inhibiting infection of the abdominal cavity organs or space. Third-generation ceftriaxon has a high permeability into tissues and a high plasma protein binding rate, which lead to a long plasma half-life of up to $8 \mathrm{~h}$. In contrast, second-generation cefotiam has a plasma half-life of $30 \mathrm{~min}$ and, therefore, is not adequate as a single-dose perioperative prophylaxis if the time to wound closure will exceed $1 \mathrm{~h}$. In cases where the surgical intervention exceeds the plasma half-life of the chosen antibiotic drug, a second dose after $3 \mathrm{~h}$ may be considered [61].

The risk of developing SSI in developed countries is very low, around $1 \%$ to $3 \%$ for clean surgery, but there is no question that this rate can be significantly reduced [62]. The drugs used should be defined in advance for each intervention, including alternatives should the patient have any contraindication against the first-choice antibiotics. Although it can be applied in the operating room, the drug is ideally applied beforehand. Application should be started immediately after intravenous access has been established (between 2 and $0.5 \mathrm{~h}$ before skin incision, as most antibiotics should reach a relevant tissue level in that time frame). If the institution carries a holding area, application might take place there; the "time out" of the surgical checklist should ensure the antibiotic was given within the appropriate time frame.

Any application of antimicrobial drugs after closure of the surgical wound should not be considered perioperative prophylaxis, as this categorisation thwarts the rationale behind the approach. Application after wound closure actually increases the risk of SSI fivefold and promotes the development of resistant bacterial strains [59, 63]. Even correctly performed "single-shot" perioperative antibiotic prophylaxis can induce severe Clostridium difficile infections and diarrhoea with highly virulent strains [64, 65]. Besides their negative and sometimes life-threatening consequences, SSIs significantly increase the length of the hospital stay and the associated costs. Because studies providing a high level of evidence for the how and when of perioperative antimicrobial prophylaxis are lacking, much research is still needed on the optimal and adequate use of well-established measures, including perioperative antimicrobial therapy, to reduce the incidence of SSI. Until then, the practical approach should be oriented along the theoretical rationale behind this intervention.

\section{MRSA}

There is an ongoing discussion about whether antibiotic prophylaxis should cover resistant bacterial strains, such as methicillin-resistant Staphylococcus aureus (MRSA), if the patient had been colonised before the surgery [66]. The data do not support the general use of perioperative prophylaxis with agents active against MRSA if the patient is colonised by resistant bacteria. Two small studies of hospitals with a high prevalence of MRSA demonstrated conflicting results for a cohort of cardiac surgery and neurosurgery patients $[67,68]$. The study in cardiac surgery patients did not demonstrate a difference in the rate of surgical wound infections when comparing vancomycin with cefazolin, whereas the same approach significantly reduced shunt infections and mortality when neurosurgical patients were studied. However, for patients at high risk of SSI, who should be identified in advance of surgery, the extension of antibiotic prophylaxis to agents against MRSA and other resistant bacterial strains might be considered.

At our University Medical Center, vancomycin is not the drug of choice for such cases because it has a high molecular weight and penetrates poorly into tissues. Clindamycin, rifampicin or fosfomycin might be used as long as the MRSA strain is sensitive to these agents; linezolid and daptomycin are additional options. 


\section{Joint decision-making}

The determination of the most effective use of preoperative and perioperative antimicrobial therapy for a patient requires efforts by a multidisciplinary team, including pivotally the anaesthesiologist and the surgeon but also the microbiologist and the nursing staff. These efforts will often require the use of a standard protocol, quality management and change. The change includes altered behaviour by surgeons and the other team members involved in the patient's care pathway through the surgical procedure and recovery [69, 70]. Quality improvement measures from industry have been successfully applied to hospital settings to achieve adequate, if not optimal, prophylactic antibiotic use [71].

Measures for avoiding postoperative complications

Major abdominal surgery per se represents a challenge for the human immune system and other systems needed for a body to adequately react to surgical stress and to maintain or restore homeostasis. In general, the degree to which the stress response of the human body will be controlled during surgery determines the body's susceptibility to minor or major postoperative complications. Measures performed to induce and maintain surgical anaesthesia can also challenge these systems. From a large range of potential interventions for ameliorating postoperative complications, this review focuses on five of the most important [41].

\section{Airway management and ventilation}

Out of 10,000 episodes of anaesthesia, documented severe aspiration occurs in 1-5 cases; aspiration might also occur unobserved during all phases of anaesthesia, from induction to recovery [72]. In an otherwise unstressed individual, this unobserved aspiration ("microaspiration") might cause no serious complications, but because the surgical intervention challenges the immune system, the lungs may be more susceptible to exposure to minor amounts of bacteria from the oral cavity. Abdominal surgery clearly carries a higher risk of postoperative pulmonary complications than other types of surgery do; measures to reduce the rate of these complications will clearly influence patient outcome [73, 74].

There is an ongoing debate on the extent to which oral hygiene measures, types of endotracheal tubing cuffs, cuff pressure control and continuous supraglottic suctioning might ameliorate postoperative pulmonary complications [75]. In a study of 86 patients who underwent oesophagectomy, the incidence of postoperative pneumonia was significantly lower among patients who brushed their teeth five times a day than among patients who used standard oral care as usual [76]. With a large cohort of post-cardiac surgery patients, Bouza et al. demonstrated the costeffectiveness of supraglottic suctioning; however, the effectiveness of this measure as an intraoperative intervention and during other types of surgery has still to be proven [77]. In 2000, the Acute Respiratory Distress Syndrome Clinical Network trial demonstrated for the first time a lower mortality in a large cohort of patients with acute lung injury or acute respiratory distress when a protective ventilatory strategy was applied using small tidal volumes and predefined positive end-expiratory pressure settings [78]. Other recent studies clearly hint that the use of protective ventilatory settings during anaesthesia in the operating room - especially during large abdominal surgery - reduce the inflammatory reaction of the human body and very likely improve patient outcome [79-81].

Induction of anaesthesia leads to atelectasis formation, predominately in the caudal-dependent parts of the lungs. Prevention and reversal of atelectasis increases functional residual capacity and improves gas exchange in the postoperative period $[82,83]$. Measures to reduce atelectasis might, therefore, reduce postoperative pulmonary complications. The usefulness of positive end-expiratory pressure intraoperatively is controversial, but Squadrone et al. have demonstrated the positive effects of applying continuous positive pressure in the recovery room after major elective abdominal surgery [84, 85].

In conclusion, oral hygiene measures and, at least in high-risk patients, the use of special endotracheal tubes clearly influence the outcome of patients who undergo major abdominal surgery. In addition, protective intraoperative ventilatory settings should be used because they influence the systemic inflammatory response to surgery and ventilation. Finally, there is good rationale to prevent or reverse atelectasis, but the number of studies supporting this approach on an evidence-based level is limited.

\section{Choice of anaesthetic agents}

The fact that anaesthetic agents modulate the response of an organism to surgical stress and hence can influence patient outcome after major abdominal surgery represents a double-edged sword. These drugs can either enhance or lower the ability of the immune system to sufficiently react to sources of infection during the postoperative period, and they can increase or decrease mesenteric perfusion [86-88]. The effect on mesenteric blood flow does not depend on whether balanced general anaesthesia (i.e. opioids combined with volatile anaesthetic agents), pure inhaled anaesthesia or pure intravenous anaesthesia is used, but on the degree to which the applied technique influences haemodynamics in general.

The combination of general anaesthesia and thoracic epidural anaesthesia (TEA) has become the technique of 
choice at many institutions for major abdominal surgery. TEA improves mesenteric blood flow, increases oxygen supply to the abdominal cavity and allows sufficient pain control after surgery (the latter represents one of the cornerstones of the fast-track surgery concept) [89-91]. Very recent studies have suggested that for some types of cancer TEA might also reduce the rate of recurrence after surgical resection. The possibility of reducing tumour recurrence makes the combination of general anaesthesia and TEA even more appealing, even if some contraindications for its use might exist [92-95].

\section{Glucose control}

Numerous studies have demonstrated the negative effects of intra-hospital hyperglycaemic phases on the rate of postoperative complications (including wound healing), nosocomial infections, length of hospital stay and mortality [96-100]. An influential study by Van de Berghe introduced the concept of intensive glucose control for critical care patients, which has been promoted and quickly applied to a more general population of intensive care patients [101]. However, studies of this approach that were performed with patients with septicaemia and in a general population of intensive care patients raised serious concerns about subsequent severe hypoglycaemia and about the effects on outcome that were originally reported $[102,103]$.

In consequence, this concept was modified toward less extreme blood glucose levels, but glucose control per se can still be regarded as a golden standard for reducing perioperative complications. The optimal glucose level in the perioperative setting has not yet been prospectively investigated. There is some evidence that in daily practice the blood glucose level should be kept between 110 and $180 \mathrm{mg} / \mathrm{dl}$ to simultaneously reduce the incidence of hyperglycaemia-related complications, such as compromise of the immune system, and to avoid hypoglycaemia [99]. Intensified glucose control requires well-trained, motivated health care staff. Accurate measurement of the actual glucose level at the bedside, or the actual value being available without delay, is also necessary.

\section{Fluid management}

Traditionally large amounts of fluids, either in the form of crystalloid solutions or as a combination of crystalloids and colloids, have been applied during major abdominal surgery [41]. However, studies on the positive effects of restrictive fluid management on postoperative complications and the concept of fast-track surgery have challenged this traditional approach and have opened up discussion on how liberal or restrictive perioperative volume therapy should be [104, 105]. Today, a more differentiated and individualised approach is suggested.

Studies have shown that in healthy individuals, restrictive (versus moderately liberal) volume replacement does not provide any beneficial effect on patient outcome. A recent review of seven prospective studies on restrictive $(998-2,740 \mathrm{ml})$ and liberal $(2,750-5,388 \mathrm{ml})$ volume replacement demonstrated inconsistent results, and the authors stated that "evidence-based guidelines for optimal procedure-specific peri-operative fixed-volume regimens cannot be formulated" [105]. However, there is evidence that high-risk surgical patients might profit from early intervention and goal-directed therapy in the perioperative phase, including the optimisation of volume status, to achieve the best rate of oxygen delivery to the cells of the body and in particular to cells involved in the mechanical and biological stress caused by the surgical intervention [106-108]. Because the rate of oxygen delivery is determined by cardiac output, volume status, contractility, peripheral resistance and oxygen content, it becomes evident that its optimisation requires extended monitoring and a multi-factorial approach.

In the monitoring of patients who receive volume therapy, there has been a clear paradigmatic shift from pressure- to volume-targeted parameters and the use of monitoring devices that are less invasive than the traditional pulmonary artery catheter. Early intervention might even include preoperative transfer to an intensive care unit (ICU) and transport of an already "optimised" patient to the operating room [109-111].

There is also ongoing debate on the best solution to use for volume replacement and volume optimisation. Studies of the use of colloidal volume replacement solutions such as hydroxyethylstarch and gelatin in intensive care medicine demonstrated that they may negatively affect patient outcome, especially renal function [102, 112-114]. However, those studies were performed in the intensive care setting, mostly with patients who had septicaemia and extended use of these substances. Even so, colloidal volume replacement acts faster than cristalloids in restoring plasma volume, a characteristic that is particularly important if a large volume is lost during the course of surgery [115]. The use of colloidal volume replacement may be contraindicated for patients with preexisting kidney problems: one study clearly demonstrated that the risk of a negative impact on kidney function increases with the preoperative renal Sequential Organ Failure Assessment score and, therefore, with the preexisting degree of renal impairment.

In summary, a moderately restrictive volume replacement strategy for uncompromised patients seems adequate; extreme volume loading definitely should be avoided. High-risk surgical patients should be identified early, monitored for plasma volume and ideally already be optimised with regard to oxygen delivery when they arrive 
at the operating room. Colloids should be made available for volume replacement during surgery because they act faster than cristalloids in restoring plasma volume and thus in ensuring oxygen supply. The amount given should not exceed $20 \mathrm{ml} / \mathrm{kg}$ body weight and day. In cases of preexisting renal impairment, the use of artificial colloids should be used more cautiously.

\section{Temperature management}

Numerous prospective randomised studies have demonstrated the negative effects of perioperative hypothermia on the duration of muscle relaxants, intraoperative blood loss, transfusion requirements, shivering, discomfort, postanaesthetic recovery, morbid cardiac events, surgical wound infections and duration of hospitalisation. Adequate control of body temperature, with warm forced-air blankets or warm fluids, is thus critical for patient outcome [116].

The efficacy of a forced-air warming system is determined mainly by the design of the blanket. During abdominal surgery, small blankets (i.e. upper body blankets and paediatric blankets) are usually used, which reduces the requirement on the airflow from the power unit. Nevertheless, the largest blanket that is feasible should be used. Forced-air warming blankets alone might not be sufficient to keep a patient normothermic throughout surgery, in cases in which large amounts of fluids are infused during the procedure, fluid warming should be employed as well.

Another approach is to pre-warm the patient. In a recently published pilot study, warming of patients before they reach the operating room reduced the postoperative degree of hypothermia, as pre-warming effectively reduces the redistribution of heat after induction of anaesthesia [117]. Effective pre-warming requires $30-60 \mathrm{~min}$ in a holding area and also the willingness of the care team to master the organizational challenges of this approach.

Intensive and intermediate postoperative care

The concept of fast-track surgery has also challenged the traditional use of ICU resources for patients who undergo major gastrointestinal surgery and are at low or moderate risk of a poor outcome. There is no rationale for transferring an extubated, stable, normothermic patient from the operating room to an ICU, and evidence is growing that transfer to a normal surgical ward might be preferred. However, this decision requires close interdisciplinary cooperation and well-defined protocols regarding how the postoperative care of the patient will be carried out. This cooperation increases the workload for the general ward and requires highly motivated well-trained nursing staff to be effective $[118,119]$.

The establishment of intermediate care wards that can deliver a higher level of care (staff and monitoring equipment) might further reduce the need for intensive care beds for highrisk patients who have undergone elective abdominal surgery. For patients who undergo major vascular surgery and thoracic surgery, the adequacy of an intermediate care unit has been demonstrated [120, 121]. Nursing, monitoring and treatment options may vary, but whatever the infrastructure of the intermediate care unit might be, it generally provides basic haemodynamic monitoring, the ability to provide one or two intravenous drugs continuously and the ability to perform non-invasive ventilation.

Patients undergoing major abdominal surgery who are at high risk of a poor outcome - particularly elderly patients and patients with underlying chronic respiratory diseasesshould be scheduled for intensive care treatment [122-124]. In addition, should extended monitoring, invasive mechanical ventilation, continuous application of several intravenous drugs or any kind of extracorporeal procedure be required, the patient must be transferred to a highdependency ICU. For these patients, even preoperative admission to an ICU and the optimisation of their preoperative status might facilitate their journey through major abdominal surgery and improve the outcome.

In summary, most patients who undergo elective major abdominal surgery do not necessarily require intensive care resources, whereas high-risk patients might even profit from preoperative care in an ICU. Ideally, a step-up-stepdown ICU can be realized that would allow the level of care to be adapted to the needs of the patient without physically changing the location of the patient [125].

\section{Postoperative management}

The care strategy for patients after surgery has shifted tremendously over time and has been influenced primarily by modern fast-track programmes (please see the accompanying article on "fast track perioperative management: physiologic principles"). Currently, there are six major elements to the postoperative recovery period (Fig. 1). All of these principles are interrelated and affect the use and effectiveness of each other. Importantly, their effectiveness also depends greatly on the availability and sufficiency of qualified nurses and physiotherapists. This dependency often represents a key bottleneck in postsurgical treatment, particularly in times of increasing economic demands. And again, close cooperation between the surgeon and anaesthesiologist is critical to the implementation of these elements.

Modern opioid-sparing analgesia

A critical factor in postoperative management is addressing continuous pain, which decreases the patient's interest in and ability for mobilisation, interferes with the performance 
of lung exercises and restricts oral nutrition. Modern principles of nonopioid- or opioid-sparing analgesia as well as regional anaesthetic techniques have been shown to reduce the rate of postoperative paralytic ileus and to accelerate postoperative recovery [126-128]. Because modern pain management is becoming increasingly complicated, more and more hospitals are implementing specialized teams ("acute pain service") that supervise postoperative pain medication. Whether continuous administration of local anaesthetics into the surgical site offers clinical benefit remains to be demonstrated [129].

Early mobilisation and prevention of venous thromboembolism

Early mobilization is critical for postoperative recovery and the prevention of postoperative complications, particularly pulmonary complications and venous thromboembolism (VTE). Numerous risk factors for VTE have been identified, including the presence of cancer, which increases the risk several-fold [130-133]. The risk for VTE is particularly high in the first few months after diagnosis and in the presence of distant metastases, and it is further increased by chemotherapy and surgery [130, 133]. While it is beyond the scope of this review to comprehensively cover this topic, practical recommendations on the prophylaxis of VTE, adjusted according to recent guidelines [131-135], are listed in Table 5.

\section{Extended lung expansion exercises}

Extended lung expansion exercise is the first and most important strategy for reducing postoperative pulmonary complications $[19,20,136]$. It is also recommended that patients with restricted pulmonary function perform these exercises before surgery. Furthermore, for patients who are at high risk of developing a pulmonary complication (see "Pulmonary risk evaluation" above), the selective but nonroutine use of nasogastric tubes is recommended [19].

Early removal of tubes, catheters and drains

Until recently, prophylactic nasogastric decompression tubes were routinely used for prolonged postoperative time periods with the intent of reducing nausea and vomiting, decreasing abdominal distension and lowering the risk of pulmonary aspiration. This clinical practice, however, is not supported by the literature [137-139]. At our University Medical Center, a nasogastric tube is only recommended as long as the retrograde fluid delivery of the tube exceeds $100 \mathrm{ml} /$ day.

The persistence of other catheters and drains is similarly problematic. Most importantly, they restrict the patient's freedom and, in most cases, limit the patient's demand for
Table 5 Practical guidelines on the prophylaxis of venous thromboembolism

In the absence of acute bleeding or other contraindications, all patients hospitalised with an acute medical illness should receive VTE prophylaxis that is commenced preoperatively.

In patients who are undergoing low-risk surgery and have no risk factors for VTE, pharmacologic prophylaxis is generally not recommended, only graduated compression stockings and frequent ambulation. In our university hospital, however, we prefer to use VTE prophylaxis for every hospitalised patient (in the absence of acute bleeding or other contraindications).

Common VTE prophylaxis options include low-dose unfractionated heparin (UFH) and low-molecular-weight heparin (LMWH). The latter is contraindicated in patients with renal insufficiency.

Patients at high risk for developing VTE should receive higher doses of either UFH or LMWH than moderate- or low-risk patients (e.g. enoxaparin 40 versus $20 \mathrm{mg}$ daily). Patients with chronic atrial fibrillation or a mechanical heart valve or who otherwise require therapeutic anticoagulation need to receive weight-adapted LMWH, twice daily, or intravenous aPTT-adjusted UFH.

Because nonemergency surgery is usually scheduled during daytime hours, subcutaneous prophylaxis should be given in the evening. For patients who require therapeutic anticoagulation, LMWH should be paused on the morning of the operation, while UFH infusion should be discontinued $4 \mathrm{~h}$ preoperatively.

In patients at low or medium risk for postoperative bleeding, LMWH should be continued on the evening after surgery and last until discharge from hospital. In patients who are at high risk for postoperative bleeding, intravenous UFH should be continued immediately after transfer to the ICU (commonly 100-200 U/h).

Patients who had undergone major abdominal or pelvic surgery for gastrointestinal malignancy should be considered for postdischarge VTE prophylaxis for up to 4 weeks after surgery in the following situations: residual or metastatic disease, obesity or previous history of VTE.

mobilisation. The placement of drains in particular is a highly debated issue [140]. The rationale of placing an intraabdominal drain after gastrointestinal surgery is to screen for postoperative haemorrhage, to identify an early enteric, bile, pancreatic or chyle leak and to allow early intervention (e.g. transfusion, interventional treatment or reoperation). In cases in which the drain adequately "controls" the leak, reoperation or intervention may even be avoided [141, 142]. Although a growing body of evidence suggests that nonemergency gastrointestinal surgery can be performed safely without prophylactic intra-abdominal drainage and that drainage may even be harmful after hepatic resection in chronic liver disease and after appendectomy, it remains highly controversial whether drainage is desirable [143, 144]. It also remains unclear, particularly for pancreatic resections, whether short-term drainage is superior to longterm drainage [144]. At our University Medical Center, we routinely place abdominal drains after major gastrointestinal surgery, primarily in order to detect complications as early as possible and to reduce the rate of relaparotomy in cases of anastomotic leak. 
Early oral nutrition

Early oral nutrition is recommended for non-emergency gastrointestinal surgery. An earlier practice had been temporary starvation; the rationale was to prevent postoperative nausea and to protect the surgical intestinal anastomosis from mechanical stress. However, several clinical trials failed to demonstrate a clear benefit for this practice (summarized in [145]), and early nutrition is now standard practice. Because postoperative nausea will prevent oral nutrition and hence limit early recovery and encourage postoperative ileus, nausea and vomiting should be treated with serotonin antagonists, low-dose dexamethasone, droperidol or dimenhydrinate [146].

\section{Early detection of complications}

The final important aspect of postoperative care is the early detection of complications. Elderly patients in particular are at increased risk for developing complications, mainly due to their reduced physiologic reserves, multiple (age-related) comorbidities, polypharmacy and a frequently altered response to commonly used drugs (altered pharmacodynamics and pharmacokinetics). Because only a small group of patients accounts for the majority of postoperative morbidity and mortality after gastrointestinal surgery, it is crucial that these high-risk patients be identified (see section "Preoperative risk assessment" above). In addition, for these patients, extra efforts must be made to prevent potential complications and to identify actual complications as early as possible [147, 148].

For elderly patients, a complication termed postoperative cognitive decline (POCD) appears to be an increasing problem. In contrast to postoperative delirium, which is defined as confusion and altered consciousness that lasts for days, POCD primarily effects memory and executive function and may last for weeks or months [149]. It is unclear how this complication can be prevented, if at all.

\section{Conclusion}

Standard perioperative management in elective gastrointestinal surgery has advanced significantly in the last decade. As a truly multidisciplinary approach, it involves close interaction between the disciplines of surgery, anaesthesiology and intensive care medicine throughout the preoperative, intraoperative and postoperative phases. Major improvements have been based on evidence (see Fig. 1), and their implementation into routine clinical practice has enabled increasingly complex surgical procedures for an ageing patient population with significant comorbidities. For these reasons, major gastrointestinal surgery can now be safely performed with acceptable morbidity and mortality rates.

Conflicts of interest None for MG and BMG; MQ is a member of the international advisory board of COVIDIEN.

Open Access This article is distributed under the terms of the Creative Commons Attribution Noncommercial License which permits any noncommercial use, distribution, and reproduction in any medium, provided the original author(s) and source are credited.

\section{References}

1. Ghaferi AA, Birkmeyer JD, Dimick JB (2009) Variation in hospital mortality associated with inpatient surgery. N Engl J Med 361(14):1368-1375

2. Jencks SF, Williams MV, Coleman EA (2009) Rehospitalizations among patients in the Medicare fee-for-service program. N Engl J Med 360(14):1418-1428

3. Deutsche Gesellschaft für Anästhesiologie und Intensivmedizin DGfIM, Deutsche Gesellschaft für Chirurgie (2010) Preoperative evaluation of adult patients prior to elective, non-cardiac surgery: joint recommendations of German Society of Anesthesiology and Intensive Care Medicine, German Society of Surgery and German Society of Internal Medicine. Anaesthesist 59(11):1041-1050

4. Ryding AD, Kumar S, Worthington AM, Burgess D (2009) Prognostic value of brain natriuretic peptide in noncardiac surgery: a meta-analysis. Anesthesiology 111(2):311-319

5. Cuthbertson BH, Amiri AR, Croal BL, Rajagopalan S, Alozairi O, Brittenden J, Hillis GS (2007) Utility of B-type natriuretic peptide in predicting perioperative cardiac events in patients undergoing major non-cardiac surgery. Br J Anaesth 99(2):170-176

6. Feringa HH, Schouten O, Dunkelgrun M, Bax JJ, Boersma E, Elhendy A, de Jonge R, Karagiannis SE, Vidakovic R, Poldermans D (2007) Plasma N-terminal pro-B-type natriuretic peptide as long-term prognostic marker after major vascular surgery. Heart 93(2):226-231

7. Ackland GL, Edwards M (2010) Defining higher-risk surgery. Curr Opin Crit Care 16(4):339-346

8. Khuri SF, Henderson WG, DePalma RG, Mosca C, Healey NA, Kumbhani DJ (2005) Determinants of long-term survival after major surgery and the adverse effect of postoperative complications. Ann Surg 242(3):326-341, discussion 341-323

9. Copeland GP, Jones D, Walters M (1991) POSSUM: a scoring system for surgical audit. Br J Surg 78(3):355-360

10. Haga Y, Ikei S, Ogawa M (1999) Estimation of Physiologic Ability and Surgical Stress (E-PASS) as a new prediction scoring system for postoperative morbidity and mortality following elective gastrointestinal surgery. Surg Today 29(3):219-225

11. Markus PM, Martell J, Leister I, Horstmann O, Brinker J, Becker H (2005) Predicting postoperative morbidity by clinical assessment. Br J Surg 92(1):101-106

12. Cohen ME, Dimick JB, Bilimoria KY, Ko CY, Richards K, Hall BL (2009) Risk adjustment in the American College of Surgeons National Surgical Quality Improvement Program: a comparison of logistic versus hierarchical modeling. J Am Coll Surg 209 (6):687-693

13. Fleisher LA, Beckman JA, Brown KA, Calkins H, Chaikof E, Fleischmann KE, Freeman WK, Froehlich JB, Kasper EK, Kersten JR, Riegel B, Robb JF, Smith SC Jr, Jacobs AK, Adams 
CD, Anderson JL, Antman EM, Buller CE, Creager MA, Ettinger SM, Faxon DP, Fuster V, Halperin JL, Hiratzka LF, Hunt SA, Lytle BW, Md RN, Ornato JP, Page RL, Riegel B, Tarkington LG, Yancy CW (2007) ACC/AHA 2007 Guidelines on Perioperative Cardiovascular Evaluation and Care for Noncardiac Surgery: Executive Summary: A Report of the American College of Cardiology/American Heart Association Task Force on Practice Guidelines (Writing Committee to Revise the 2002 Guidelines on Perioperative Cardiovascular Evaluation for Noncardiac Surgery): Developed in Collaboration With the American Society of Echocardiography, American Society of Nuclear Cardiology, Heart Rhythm Society, Society of Cardiovascular Anesthesiologists, Society for Cardiovascular Angiography and Interventions, Society for Vascular Medicine and Biology, and Society for Vascular Surgery. Circulation 116(17):1971-1996

14. Poldermans D, Bax JJ, Boersma E, De Hert S, Eeckhout E, Fowkes G, Gorenek B, Hennerici MG, Lung B, Kelm M, Kjeldsen KP, Kristensen SD, Lopez-Sendon J, Pelosi P, Philippe F, Pierard L, Ponikowski P, Schmid JP, Sellevold OF, Sicari R, Van den Berghe G, Vermassen F, Hoeks SE, Vanhorebeek I (2009) Guidelines for pre-operative cardiac risk assessment and perioperative cardiac management in non-cardiac surgery: the Task Force for Preoperative Cardiac Risk Assessment and Perioperative Cardiac Management in Non-cardiac Surgery of the European Society of Cardiology (ESC) and European Society of Anaesthesiology (ESA). Eur Heart J 30(22):2769-2812

15. Williams FM, Bergin JD (2009) Cardiac screening before noncardiac surgery. Surg Clin North Am 89(4):747-762, vii

16. Froehlich JB, Fleisher LA (2009) Noncardiac surgery in the patient with heart disease. Anesthesiol Clin 27(4):649-671

17. Hammill BG, Curtis LH, Bennett-Guerrero E, O'Connor CM, Jollis JG, Schulman KA, Hernandez AF (2008) Impact of heart failure on patients undergoing major noncardiac surgery. Anesthesiology 108(4):559-567

18. Smetana GW, Lawrence VA, Cornell JE (2006) Preoperative pulmonary risk stratification for noncardiothoracic surgery: systematic review for the American College of Physicians. Ann Intern Med 144(8):581-595

19. Qaseem A, Snow V, Fitterman N, Hornbake ER, Lawrence VA, Smetana GW, Weiss K, Owens DK, Aronson M, Barry P, Casey DE Jr, Cross JT Jr, Fitterman N, Sherif KD, Weiss KB (2006) Risk assessment for and strategies to reduce perioperative pulmonary complications for patients undergoing noncardiothoracic surgery: a guideline from the American College of Physicians. Ann Intern Med 144(8):575-580

20. Cook MW, Lisco SJ (2009) Prevention of postoperative pulmonary complications. Int Anesthesiol Clin 47(4):65-88

21. Fleischmann KE, Beckman JA, Buller CE, Calkins $H$, Fleisher LA, Freeman WK, Froehlich JB, Kasper EK, Kersten JR, Robb JF, Valentine RJ (2009) 2009 ACCF/AHA focused update on perioperative beta blockade. J Am Coll Cardiol 54 (22):2102-2128

22. Duncan AI, Koch CG, Xu M, Manlapaz M, Batdorf B, Pitas G, Starr N (2007) Recent metformin ingestion does not increase inhospital morbidity or mortality after cardiac surgery. Anesth Analg 104(1):42-50

23. Grines CL, Bonow RO, Casey DE Jr, Gardner TJ, Lockhart PB, Moliterno DJ, O'Gara P, Whitlow P (2007) Prevention of premature discontinuation of dual anti-platelet therapy in patients with coronary artery stents: a science advisory from the American Heart Association, American College of Cardiology, Society for Cardiovascular Angiography and Interventions, American College of Surgeons, and American Dental Association, with representation from the American College of Physicians. Circulation 115(6):813-818
24. Jambor C, Spannagl M, Zwissler B (2009) Perioperative management of patients with coronary stents in non-cardiac surgery. Anaesthesist 58(10):971-985

25. Popescu WM (2010) Perioperative management of the patient with a coronary stent. Curr Opin Anaesthesiol 23(1):109-115

26. Brennan KA, Genever RW (2010) Managing Parkinson's disease during surgery. BMJ 341:c5718

27. Stevenson WG, Chaitman BR, Ellenbogen KA, Epstein AE, Gross WL, Hayes DL, Strickberger SA, Sweeney MO (2004) Clinical assessment and management of patients with implanted cardioverter-defibrillators presenting to nonelectrophysiologists. Circulation 110(25):3866-3869

28. American Society of Anesthesiologists Task Force on Perioperative Management of Patients with Cardiac Rhythm Management Devices (2005) Practice advisory for the perioperative management of patients with cardiac rhythm management devices: pacemakers and implantable cardioverter-defibrillators. Anesthesiology 103(1):186-198

29. Rozner MA (2007) The patient with a cardiac pacemaker or implanted defibrillator and management during anaesthesia. Curr Opin Anaesthesiol 20(3):261-268

30. Kehlet H (1997) Multimodal approach to control postoperative pathophysiology and rehabilitation. Br J Anaesth 78(5):606-617

31. Kehlet H, Dahl JB (2003) Anaesthesia, surgery, and challenges in postoperative recovery. Lancet 362(9399):1921-1928

32. Kehlet H, Wilmore DW (2008) Evidence-based surgical care and the evolution of fast-track surgery. Ann Surg 248(2):189-198

33. Kehlet H (2008) Fast-track colorectal surgery. Lancet 371 (9615):791-793

34. Burke P, Mealy K, Gillen P, Joyce W, Traynor O, Hyland J (1994) Requirement for bowel preparation in colorectal surgery. Br J Surg 81(6):907-910

35. Santos JC Jr, Batista J, Sirimarco MT, Guimaraes AS, Levy CE (1994) Prospective randomized trial of mechanical bowel preparation in patients undergoing elective colorectal surgery. Br J Surg 81(11):1673-1676

36. Miettinen RP, Laitinen ST, Makela JT, Paakkonen ME (2000) Bowel preparation with oral polyethylene glycol electrolyte solution vs. no preparation in elective open colorectal surgery: prospective, randomized study. Dis Colon Rectum 43(5):669675, discussion 675-667

37. Zmora O, Mahajna A, Bar-Zakai B, Rosin D, Hershko D, Shabtai M, Krausz MM, Ayalon A (2003) Colon and rectal surgery without mechanical bowel preparation: a randomized prospective trial. Ann Surg 237(3):363-367

38. Pena-Soria MJ, Mayol JM, Anula R, Arbeo-Escolar A, Fernandez-Represa JA (2008) Single-blinded randomized trial of mechanical bowel preparation for colon surgery with primary intraperitoneal anastomosis. J Gastrointest Surg 12(12):21032108, discussion 2108-2109

39. Pineda CE, Shelton AA, Hernandez-Boussard T, Morton JM, Welton ML (2008) Mechanical bowel preparation in intestinal surgery: a meta-analysis and review of the literature. J Gastrointest Surg 12(11):2037-2044

40. Bretagnol F, Panis Y, Rullier E, Rouanet P, Berdah S, Dousset B, Portier G, Benoist S, Chipponi J, Vicaut E (2010) Rectal cancer surgery with or without bowel preparation: the French GRECCAR III multicenter single-blinded randomized trial. Ann Surg 252(5):863-868

41. Banz VM, Jakob SM, Inderbitzin D (2010) Improving outcome after major surgery: pathophysiological considerations. Anesth Analg, 2010 Aug 24

42. Lindstrom D, Sadr Azodi O, Wladis A, Tonnesen H, Linder S, Nasell H, Ponzer S, Adami J (2008) Effects of a perioperative smoking cessation intervention on postoperative complications: a randomized trial. Ann Surg 248(5):739-745 
43. Thomsen T, Tonnesen H, Moller AM (2009) Effect of preoperative smoking cessation interventions on postoperative complications and smoking cessation. Br J Surg 96(5):451-461

44. Windsor A, Braga M, Martindale R, Buenos R, Tepaske R, Kraehenbuehl L, Weimann A (2004) Fit for surgery: an expert panel review on optimising patients prior to surgery, with a particular focus on nutrition. Surgeon 2(6):315-319

45. Gibbs J, Cull W, Henderson W, Daley J, Hur K, Khuri SF (1999) Preoperative serum albumin level as a predictor of operative mortality and morbidity: results from the National VA Surgical Risk Study. Arch Surg 134(1):36-42

46. Bozzetti F, Gavazzi C, Miceli R, Rossi N, Mariani L, Cozzaglio L, Bonfanti G, Piacenza S (2000) Perioperative total parenteral nutrition in malnourished, gastrointestinal cancer patients: a randomized, clinical trial. JPEN J Parenter Enteral Nutr 24(1):714

47. Bozzetti F, Gianotti L, Braga M, Di Carlo V, Mariani L (2007) Postoperative complications in gastrointestinal cancer patients: the joint role of the nutritional status and the nutritional support. Clin Nutr 26(6):698-709

48. Koretz RL, Lipman TO, Klein S (2001) AGA technical review on parenteral nutrition. Gastroenterology 121(4):970-1001

49. Merkow RP, Bilimoria KY, McCarter MD, Bentrem DJ (2009) Effect of body mass index on short-term outcomes after colectomy for cancer. J Am Coll Surg 208(1):53-61

50. Tokunaga M, Hiki N, Fukunaga $T$, Ogura $T$, Miyata $S$, Yamaguchi T (2009) Effect of individual fat areas on early surgical outcomes after open gastrectomy for gastric cancer. Br J Surg 96(5):496-500

51. Flum DR, Belle SH, King WC, Wahed AS, Berk P, Chapman W, Pories W, Courcoulas A, McCloskey C, Mitchell J, Patterson E, Pomp A, Staten MA, Yanovski SZ, Thirlby R, Wolfe B (2009) Perioperative safety in the longitudinal assessment of bariatric surgery. N Engl J Med 361(5):445-454

52. Sahai SK, Zalpour A, Rozner MA (2010) Preoperative evaluation of the oncology patient. Med Clin North Am 94(2):403-419

53. Youssef G, Links M (2005) The prevention and management of cardiovascular complications of chemotherapy in patients with cancer. Am J Cardiovasc Drugs 5(4):233-243

54. Werner-Wasik M, Yorke E, Deasy J, Nam J, Marks LB (2010) Radiation dose-volume effects in the esophagus. Int J Radiat Oncol Biol Phys 76(3 Suppl):S86-S93

55. Kavanagh BD, Pan CC, Dawson LA, Das SK, Li XA, Ten Haken RK, Miften M (2010) Radiation dose-volume effects in the stomach and small bowel. Int J Radiat Oncol Biol Phys 76(3 Suppl):S101-S107

56. Haynes AB, Weiser TG, Berry WR, Lipsitz SR, Breizat AH, Dellinger EP, Herbosa T, Joseph S, Kibatala PL, Lapitan MC, Merry AF, Moorthy K, Reznick RK, Taylor B, Gawande AA (2009) A surgical safety checklist to reduce morbidity and mortality in a global population. N Engl J Med 360(5):491-499

57. de Vries EN, Prins HA, Crolla RM, den Outer AJ, van Andel G, van Helden SH, Schlack WS, van Putten MA, Gouma DJ, Dijkgraaf MG, Smorenburg SM, Boermeester MA (2010) Effect of a comprehensive surgical safety system on patient outcomes. N Engl J Med 363(20):1928-1937

58. Stone HH, Hooper CA, Kolb LD, Geheber CE, Dawkins EJ (1976) Antibiotic prophylaxis in gastric, biliary and colonic surgery. Ann Surg 184(4):443-452

59. Classen DC, Evans RS, Pestotnik SL, Horn SD, Menlove RL, Burke JP (1992) The timing of prophylactic administration of antibiotics and the risk of surgical-wound infection. N Engl J Med 326(5):281-286

60. Bratzler DW, Houck PM (2005) Antimicrobial prophylaxis for surgery: an advisory statement from the National Surgical Infection Prevention Project. Am J Surg 189(4):395-404
61. Edmiston CE, Krepel C, Kelly H, Larson J, Andris D, Hennen C, Nakeeb A, Wallace JR (2004) Perioperative antibiotic prophylaxis in the gastric bypass patient: do we achieve therapeutic levels? Surgery 136(4):738-747

62. Uckay I, Harbarth S, Peter R, Lew D, Hoffmeyer P, Pittet D (2010) Preventing surgical site infections. Expert Rev Anti Infect Ther 8(6):657-670

63. Manian FA, Meyer PL, Setzer J, Senkel D (2003) Surgical site infections associated with methicillin-resistant Staphylococcus aureus: do postoperative factors play a role? Clin Infect Dis 36 (7):863-868

64. Crabtree TD, Pelletier SJ, Gleason TG, Pruett TL, Sawyer RG (1999) Clinical characteristics and antibiotic utilization in surgical patients with Clostridium difficile-associated diarrhea. Am Surg 65(6):507-511, discussion 511-502

65. Carignan A, Allard C, Pepin J, Cossette B, Nault V, Valiquette L (2008) Risk of Clostridium difficile infection after perioperative antibacterial prophylaxis before and during an outbreak of infection due to a hypervirulent strain. Clin Infect Dis 46 (12): $1838-1843$

66. Butterly A, Schmidt U, Wiener-Kronish J (2010) Methicillinresistant Staphylococcus aureus colonization, its relationship to nosocomial infection, and efficacy of control methods. Anesthesiology 113(6):1453-1459

67. Finkelstein R, Rabino G, Mashiah T, Bar-El Y, Adler Z, Kertzman V, Cohen O, Milo S (2002) Vancomycin versus cefazolin prophylaxis for cardiac surgery in the setting of a high prevalence of methicillin-resistant staphylococcal infections. J Thorac Cardiovasc Surg 123(2):326-332

68. Tacconelli E, Cataldo MA, Albanese A, Tumbarello M, Arduini E, Spanu T, Fadda G, Anile C, Maira G, Federico G, Cauda R (2008) Vancomycin versus cefazolin prophylaxis for cerebrospinal shunt placement in a hospital with a high prevalence of meticillin-resistant Staphylococcus aureus. J Hosp Infect 69 (4):337-344

69. Diana $M$, Hübner $M$, Eisenring $M$, Zanetti $G$, Troillet $N$, Demartines N (2011) Measures to prevent surgical site infections: what surgeons (should) do. World J Surg 35 (2):280-288

70. Klein J (2008) Multimodal multidisciplinary standardization of perioperative care: still a long way to go. Curr Opin Anaesthesiol 21(2):187-190

71. Burkitt KH, Mor MK, Jain R, Kruszewski MS, McCray EE, Moreland ME, Muder RR, Obrosky DS, Sevick MA, Wilson MA, Fine MJ (2009) Toyota production system quality improvement initiative improves perioperative antibiotic therapy. Am J Manag Care 15(9):633-642

72. Benington S, Severn A (2007) Preventing aspiration and regurgitation. Anaesthesia Intensive Care Med 8:368-372

73. Smetana GW, Cohn SL, Lawrence VA (2004) Update in perioperative medicine. Ann Intern Med 140(6):452-461

74. Cohn SL, Smetana GW (2007) Update in perioperative medicine. Ann Intern Med 147(4):263-270

75. Warner DO (2000) Preventing postoperative pulmonary complications: the role of the anesthesiologist. Anesthesiology 92 (5):1467-1472

76. Akutsu Y, Matsubara H, Shuto K, Shiratori T, Uesato M, Miyazawa Y, Hoshino I, Murakami K, Usui A, Kano M, Miyauchi H (2010) Pre-operative dental brushing can reduce the risk of postoperative pneumonia in esophageal cancer patients. Surgery 147(4):497-502

77. Bouza E, Perez MJ, Munoz P, Rincon C, Barrio JM, Hortal J (2008) Continuous aspiration of subglottic secretions in the prevention of ventilator-associated pneumonia in the postoperative period of major heart surgery. Chest 134(5):938946 
78. The Acute Respiratory Distress Syndrome Network (2000) Ventilation with lower tidal volumes as compared with traditional tidal volumes for acute lung injury and the acute respiratory distress syndrome. The Acute Respiratory Distress Syndrome Network. N Engl J Med 342(18):1301-1308

79. Michelet P, D'Journo XB, Roch A, Doddoli C, Marin V, Papazian L, Decamps I, Bregeon F, Thomas P, Auffray JP (2006) Protective ventilation influences systemic inflammation after esophagectomy: a randomized controlled study. Anesthesiology 105(5):911-919

80. Fernandez-Perez ER, Sprung J, Afessa B, Warner DO, Vachon CM, Schroeder DR, Brown DR, Hubmayr RD, Gajic O (2009) Intraoperative ventilator settings and acute lung injury after elective surgery: a nested case control study. Thorax 64(2):121127

81. Hans GA, Sottiaux TM, Lamy ML, Joris JL (2009) Ventilatory management during routine general anaesthesia. Eur J Anaesthesiol 26(1):1-8

82. Magnusson L, Spahn DR (2003) New concepts of atelectasis during general anaesthesia. Br J Anaesth 91(1):61-72

83. Duggan M, Kavanagh BP (2005) Pulmonary atelectasis: a pathogenic perioperative entity. Anesthesiology 102(4):838854

84. Imberger G, McIlroy D, Pace NL, Wetterslev J, Brok J, Moller AM (2010) Positive end-expiratory pressure (PEEP) during anaesthesia for the prevention of mortality and postoperative pulmonary complications. Cochrane Database Syst Rev 9: CD007922

85. Squadrone V, Coha M, Cerutti E, Schellino MM, Biolino P, Occella P, Belloni G, Vilianis G, Fiore G, Cavallo F, Ranieri VM (2005) Continuous positive airway pressure for treatment of postoperative hypoxemia: a randomized controlled trial. JAMA 293(5):589-595

86. Kurosawa S, Kato M (2008) Anesthetics, immune cells, and immune responses. J Anesth 22(3):263-277

87. Schneemilch CE, Schilling T, Bank U (2004) Effects of general anaesthesia on inflammation. Best Pract Res Clin Anaesthesiol 18(3):493-507

88. Ahlers O, Nachtigall I, Lenze J, Goldmann A, Schulte E, Hohne C, Fritz G, Keh D (2008) Intraoperative thoracic epidural anaesthesia attenuates stress-induced immunosuppression in patients undergoing major abdominal surgery. Br J Anaesth 101(6):781-787

89. Kabon B, Fleischmann E, Treschan T, Taguchi A, Kapral S, Kurz A (2003) Thoracic epidural anesthesia increases tissue oxygenation during major abdominal surgery. Anesth Analg 97 (6): 1812-1817

90. Moraca RJ, Sheldon DG, Thirlby RC (2003) The role of epidural anesthesia and analgesia in surgical practice. Ann Surg 238 (5):663-673

91. Fotiadis RJ, Badvie S, Weston MD, Allen-Mersh TG (2004) Epidural analgesia in gastrointestinal surgery. Br J Surg 91 (7):828-841

92. Wuethrich PY, Hsu Schmitz SF, Kessler TM, Thalmann GN, Studer UE, Stueber F, Burkhard FC (2010) Potential influence of the anesthetic technique used during open radical prostatectomy on prostate cancer-related outcome: a retrospective study. Anesthesiology 113(3):570-576

93. Snyder GL, Greenberg S (2010) Effect of anaesthetic technique and other perioperative factors on cancer recurrence. $\mathrm{Br} \mathrm{J}$ Anaesth 105(2):106-115

94. Gottschalk A, Ford JG, Regelin CC, You J, Mascha EJ, Sessler DI, Durieux ME, Nemergut EC (2010) Association between epidural analgesia and cancer recurrence after colorectal cancer surgery. Anesthesiology 113(1):27-34

95. Tsui BC, Rashiq S, Schopflocher D, Murtha A, Broemling S, Pillay J, Finucane BT (2010) Epidural anesthesia and cancer recurrence rates after radical prostatectomy. Can J Anaesth 57 (2): $107-112$

96. Cheadle WG (2006) Risk factors for surgical site infection. Surg Infect (Larchmt) 7(Suppl 1):S7-S11

97. Latham R, Lancaster AD, Covington JF, Pirolo JS, Thomas CS (2001) The association of diabetes and glucose control with surgical-site infections among cardiothoracic surgery patients. Infect Control Hosp Epidemiol 22(10):607-612

98. Capes SE, Hunt D, Malmberg K, Gerstein HC (2000) Stress hyperglycaemia and increased risk of death after myocardial infarction in patients with and without diabetes: a systematic overview. Lancet 355(9206):773-778

99. Mauermann WJ, Nemergut EC (2006) The anesthesiologist's role in the prevention of surgical site infections. Anesthesiology 105 (2):413-421

100. Ganai S, Lee KF, Merrill A, Lee MH, Bellantonio S, Brennan M, Lindenauer P (2007) Adverse outcomes of geriatric patients undergoing abdominal surgery who are at high risk for delirium. Arch Surg 142(11):1072-1078

101. van den Berghe G, Wouters P, Weekers F, Verwaest C, Bruyninckx F, Schetz M, Vlasselaers D, Ferdinande P, Lauwers P, Bouillon R (2001) Intensive insulin therapy in the critically ill patients. N Engl J Med 345(19):1359-1367

102. Brunkhorst FM, Engel C, Bloos F, Meier-Hellmann A, Ragaller M, Weiler N, Moerer O, Gruendling M, Oppert M, Grond S, Olthoff D, Jaschinski U, John S, Rossaint R, Welte T, Schaefer M, Kern P, Kuhnt E, Kiehntopf M, Hartog C, Natanson C, Loeffler M, Reinhart K (2008) Intensive insulin therapy and pentastarch resuscitation in severe sepsis. N Engl $\mathrm{J}$ Med 358 (2):125-139

103. Finfer S, Chittock DR, Su SY, Blair D, Foster D, Dhingra V, Bellomo R, Cook D, Dodek P, Henderson WR, Hebert PC, Heritier S, Heyland DK, McArthur C, McDonald E, Mitchell I, Myburgh JA, Norton R, Potter J, Robinson BG, Ronco JJ (2009) Intensive versus conventional glucose control in critically ill patients. N Engl J Med 360(13):1283-1297

104. Kehlet H (2009) Principles of fast track surgery. Multimodal perioperative therapy programme. Chirurg 80(8):687-689

105. Bundgaard-Nielsen M, Secher NH, Kehlet H (2009) 'Liberal' vs. 'restrictive' perioperative fluid therapy-a critical assessment of the evidence. Acta Anaesthesiol Scand 53(7):843-851

106. Holte K, Foss NB, Andersen J, Valentiner L, Lund C, Bie P, Kehlet $H$ (2007) Liberal or restrictive fluid administration in fasttrack colonic surgery: a randomized, double-blind study. $\mathrm{Br} \mathrm{J}$ Anaesth 99(4):500-508

107. Futier E, Constantin JM, Petit A, Chanques G, Kwiatkowski F, Flamein R, Slim K, Sapin V, Jaber S, Bazin JE (2010) Conservative vs restrictive individualized goal-directed fluid replacement strategy in major abdominal surgery: a prospective randomized trial. Arch Surg 145(12):1193-1200

108. Donati A, Loggi S, Preiser JC, Orsetti G, Munch C, Gabbanelli V, Pelaia P, Pietropaoli P (2007) Goal-directed intraoperative therapy reduces morbidity and length of hospital stay in high-risk surgical patients. Chest 132(6):1817-1824

109. Forget P, Lois F, de Kock M (2010) Goal-directed fluid management based on the pulse oximeter-derived pleth variability index reduces lactate levels and improves fluid management. Anesth Analg 111(4):910-914

110. Benes J, Chytra I, Altmann P, Hluchy M, Kasal E, Svitak R, Pradl R, Stepan M (2010) Intraoperative fluid optimization using stroke volume variation in high risk surgical patients: results of prospective randomized study. Crit Care 14(3):R118

111. Futier E, Robin E, Jabaudon M, Guerin R, Petit A, Bazin JE, Constantin JM, Vallet B (2010) Central venous O saturation and venous-to-arterial $\mathrm{CO}$ difference as complementary tools for goaldirected therapy during high-risk surgery. Crit Care 14(5):R193 
112. Schortgen F, Lacherade JC, Bruneel F, Cattaneo I, Hemery F, Lemaire F, Brochard L (2001) Effects of hydroxyethylstarch and gelatin on renal function in severe sepsis: a multicentre randomised study. Lancet 357(9260):911-916

113. Schortgen F, Girou E, Deye N, Brochard L (2008) The risk associated with hyperoncotic colloids in patients with shock. Intensive Care Med 34(12):2157-2168

114. Sakr Y, Payen D, Reinhart K, Sipmann FS, Zavala E, Bewley J, Marx G, Vincent JL (2007) Effects of hydroxyethyl starch administration on renal function in critically ill patients. Br J Anaesth 98(2):216-224

115. Marx G, Pedder S, Smith L, Swaraj S, Grime S, Stockdale H, Leuwer M (2004) Resuscitation from septic shock with capillary leakage: hydroxyethyl starch $(130 \mathrm{kd})$, but not Ringer's solution maintains plasma volume and systemic oxygenation. Shock 21(4):336-341

116. Brauer A, Quintel M (2009) Forced-air warming: technology, physical background and practical aspects. Curr Opin Anaesthesiol 22(6):769-774

117. Brauer A, Waeschle RM, Heise D, Perl T, Hinz J, Quintel M, Bauer M (2010) Preoperative pre-warming as a routine measure. First experiences. Anaesthesist 59(9):842-850

118. Park GR, Evans TN, Hutchins J, Borissov B, Gunning KE, Klinck JR (2000) Reducing the demand for admission to intensive care after major abdominal surgery by a change in anaesthetic practice and the use of remifentanil. Eur J Anaesthesiol 17(2):111-119

119. Scatizzi M, Kroning KC, Boddi V, De Prizio M, Feroci F (2010) Fast-track surgery after laparoscopic colorectal surgery: is it feasible in a general surgery unit? Surgery 147 (2):219-226

120. Ryan D, McGreal G (2010) Why routine intensive care unit admission after elective open infrarenal Abdominal Aortic Aneurysm repair is no longer an evidence based practice. Surgeon 8(6):297-302

121. Schweizer A, Khatchatourian G, Hohn L, Spiliopoulos A, Romand J, Licker M (2002) Opening of a new postanesthesia care unit: impact on critical care utilization and complications following major vascular and thoracic surgery. J Clin Anesth 14 (7):486-493

122. Aguilar-Nascimento JE, Salomao AB, Caporossi C, Diniz BN (2010) Clinical benefits after the implementation of a multimodal perioperative protocol in elderly patients. Arq Gastroenterol 47 (2): $178-183$

123. Young HD, Tanga MR, Wellington JL (1971) Major abdominal surgery in the elderly: a review of 172 consecutive patients. Can J Surg 14(5):324-327

124. Licker M, Schweizer A, Ellenberger C, Tschopp JM, Diaper J, Clergue F (2007) Perioperative medical management of patients with COPD. Int J Chron Obstruct Pulmon Dis 2(4):493-515

125. Vincent JL, Burchardi H (1999) Do we need intermediate care units? Intensive Care Med 25(12):1345-1349

126. White PF (2008) Multimodal analgesia: its role in preventing postoperative pain. Curr Opin Investig Drugs 9(1):76-82

127. White PF, Kehlet H, Neal JM, Schricker T, Carr DB, Carli F (2007) The role of the anesthesiologist in fast-track surgery: from multimodal analgesia to perioperative medical care. Anesth Analg 104(6):1380-1396

128. Kehlet H (2008) Postoperative ileus-an update on preventive techniques. Nat Clin Pract Gastroenterol Hepatol 5(10):552-558

129. Kehlet H, Kristensen BB (2009) Local anesthetics in the surgical wound-is the pendulum swinging toward increased use? Reg Anesth Pain Med 34(5):389-390

130. Blom JW, Doggen CJ, Osanto S, Rosendaal FR (2005) Malignancies, prothrombotic mutations, and the risk of venous thrombosis. JAMA 293(6):715-722
131. Lyman GH, Khorana AA, Falanga A, Clarke-Pearson D, Flowers C, Jahanzeb M, Kakkar A, Kuderer NM, Levine MN, Liebman H, Mendelson D, Raskob G, Somerfield MR, Thodiyil P, Trent D, Francis CW (2007) American Society of Clinical Oncology guideline: recommendations for venous thromboembolism prophylaxis and treatment in patients with cancer. J Clin Oncol 25 (34):5490-5505

132. Geerts WH, Bergqvist D, Pineo GF, Heit JA, Samama CM, Lassen MR, Colwell CW (2008) Prevention of venous thromboembolism: American College of Chest Physicians Evidence-Based Clinical Practice Guidelines (8th Edition). Chest 133(6 Suppl):381S-453S

133. Noble S, Pasi J (2010) Epidemiology and pathophysiology of cancer-associated thrombosis. Br J Cancer 102(Suppl 1):S2-S9

134. Stanley A, Young A (2010) Primary prevention of venous thromboembolism in medical and surgical oncology patients. $\mathrm{Br}$ J Cancer 102(Suppl 1):S10-S16

135. Coleman R, MacCallum P (2010) Treatment and secondary prevention of venous thromboembolism in cancer. Br J Cancer 102(Suppl 1):S17-S23

136. Lawrence VA, Cornell JE, Smetana GW (2006) Strategies to reduce postoperative pulmonary complications after noncardiothoracic surgery: systematic review for the American College of Physicians. Ann Intern Med 144(8):596-608

137. Cheatham ML, Chapman WC, Key SP, Sawyers JL (1995) A meta-analysis of selective versus routine nasogastric decompression after elective laparotomy. Ann Surg 221(5):469-476, discussion 476-468

138. Nelson R, Tse B, Edwards S (2005) Systematic review of prophylactic nasogastric decompression after abdominal operations. Br J Surg 92(6):673-680

139. Yang Z, Zheng Q, Wang Z (2008) Meta-analysis of the need for nasogastric or nasojejunal decompression after gastrectomy for gastric cancer. Br J Surg 95(7):809-816

140. Buchler MW, Friess H (2006) Evidence forward, drainage on retreat: still we ignore and drain!? Ann Surg 244(1):8-9

141. Dougherty SH, Simmons RL (1992) The biology and practice of surgical drains. Part 1. Curr Probl Surg 29(8):559-623

142. Dougherty SH, Simmons RL (1992) The biology and practice of surgical drains. Part II. Curr Probl Surg 29(9):633-730

143. Petrowsky H, Demartines N, Rousson V, Clavien PA (2004) Evidence-based value of prophylactic drainage in gastrointestinal surgery: a systematic review and meta-analyses. Ann Surg 240 (6):1074-1084, discussion 1084-1075

144. Diener MK, Mehr KT, Wente MN, Kieser M, Buchler MW, Seiler CM (2011) Risk-benefit assessment of closed intraabdominal drains after pancreatic surgery: a systematic review and meta-analysis assessing the current state of evidence. Langenbecks Arch Surg 396(1):41-52

145. Lewis SJ, Egger M, Sylvester PA, Thomas S (2001) Early enteral feeding versus "nil by mouth" after gastrointestinal surgery: systematic review and meta-analysis of controlled trials. BMJ 323(7316):773-776

146. Gan TJ, Meyer TA, Apfel CC, Chung F, Davis PJ, Habib AS, Hooper VD, Kovac AL, Kranke P, Myles P, Philip BK, Samsa G, Sessler DI, Temo J, Tramer MR, Vander Kolk C, Watcha M (2007) Society for Ambulatory Anesthesia guidelines for the management of postoperative nausea and vomiting. Anesth Analg 105(6):1615-1628

147. Lees N, Hamilton M, Rhodes A (2009) Clinical review: goaldirected therapy in high risk surgical patients. Crit Care 13 (5):231

148. Jhanji S, Pearse RM (2009) The use of early intervention to prevent postoperative complications. Curr Opin Crit Care 15(4):349-354

149. Singh A, Antognini JF (2010) Perioperative pharmacology in elderly patients. Curr Opin Anaesthesiol 23(4):449-454 